www.jmscr.igmpublication.org

Impact Factor (SJIF): 6.379

Index Copernicus Value: 79.54

ISSN (e)-2347-176x ISSN (p) 2455-0450

crossrefDOI: https://dx.doi.org/10.18535/jmscr/v6i12.110

Journal Of Medical Science And Clinical Research

IGM Publication

An Official Publication of IGM Publication

\title{
Primary Resection and Anastomosis in Gangrenous Sigmoid Volvulus- A Prospective Study
}

\author{
Authors \\ Prof Dr Braja Mohan Mishra ${ }^{1}$, Dr Sandeep Mishra ${ }^{2}$, Dr Bishwajyoti Sahoo ${ }^{3 *}$ \\ ${ }^{1}$ Prof and HOD, ${ }^{2}$ Senior Resident, ${ }^{3}$ Junior Resident \\ Dept of General Surgery, VIMSAR, Burla, Sambalpur, Odisha, India \\ *Corresponding Author \\ Dr Bishwajyoti Sahoo \\ Junior Resident, Dept of General Surgery, VIMSAR, Burla, Sambalpur, Odisha, India \\ Email: sahoobishwajyoti@gmail.com, Mobile: 7377664969
}

\begin{abstract}
Introduction: The management of sigmoid volvulus has remained a controversial issue to many surgeons. Rapid resection with colostomy fashioning has been done over time for gangrenous volvulus. However resection and primary anastomosis has also been described with less complications and a shorter hospital stay. Our aim was to study the safety and efficacy of emergency resection and primary anastomosis in gangrenous sigmoid volvulus without a proximal colostomy.

Materials and Methods: It was a prospective observational study at VIMSAR, Burla, Surgery dept. from October 2016 to July 2018. Includes all gangrenous volvulus cases who were subjected to emergency resection and primary anastomosis without proximal stoma. Cardiorespiratory unstable patients and obstruction due to malignant cases were excluded. Primary outcomes studied were faecal fistula, wound infection, intestinal obstruction and mortality. Follow up period was 2 months.

Results: Total 32 cases were having gangrenous volvulus. 8 cases we did Hartmann's procedure due to distal mobilisation of bowel could not be done due to extension of gangrene. So we did Primary resection and anastomosis in 24 cases. Out of 24 cases (15 males and 9 females) there were two cases of anastomotic leak and fecal fistula( $8.33 \%)$, seven cases of wound infection(29.16\%), four cases of paralytic ileus(16.66\%), one in shock(4.16\%), one chest complication(4.16\%) and mortality(12.5\%).

Conclusion: Resection and primary anastomosis in gangrenous volvulus can be practised with few complications and a shorter hospital stay.

Keywords: Sigmoid volvulus, Gangrene, Primary anastomosis.
\end{abstract}

\section{Introduction}

Volvulus occurs when an air filled segment of the intestine twists about its mesentery ${ }^{(1)}$. Sigmoid volvulus is the most common type of volvulus and it accounts $5-7 \%$ of all intestinal obstruction ${ }^{(2)}$. It is the third common cause for intestinal obstruction in western countries after cancer and diverticular disease ${ }^{(3)}$. Sigmoid volvulus is common in both sexes, but generally occurs in elderly male ${ }^{(4)}$. Several etiological factors have been suggested including chronic constipation, long sigmoid loop with a narrow mesentery, high fibre diet, use of laxatives and Chaga's disease, pregnancy ${ }^{(5,6)}$. Acute sigmoid volvulus is an 
emergency if left untreated leads to complications like bowel ischemia, gangrene and perforation ${ }^{(7)}$. Patients present with abdominal distension, colicky abdominal pain, obstipation, vomiting and an empty, distended rectumon digital rectal examination. In gangrene of the sigmoid colon finger may be stained with blood ${ }^{(8,9)}$. Fever, shock and leukocytosis are heralds of gangrene and perforation $^{(10)}$. Plain abdominal $\mathrm{X}$ ray confirm the diagnosis in $80 \%$ of the cases ${ }^{(11)}$. A "coffee bean" sign or "omega loop" sign or "bent in inner tube" sign is seen classically on $\mathrm{X}$ ray abdomen whereas barium enema shows pathognomic “ bird's beak sign" ${ }^{(6)}$. However barium enema is contraindicated when gangrene is suspected ${ }^{(12)}$. A CT scan shows typical finding of "whirl sign"(13).

Management of sigmoid volvulus has been a constant topic of debate. In gangrenous cases Colostomy after volvulus resection entails more morbidity like stoma related complications, second surgery to maintain intestinal continuity and its mortality ${ }^{(14)}$.

The aim of the study was whether single stage resection and anastomosis of sigmoid volvulus without a proximal stoma is safe and effective in gangrenous volvulus cases and to know its outcome. This can avoid complications of a stoma and second surgery.

\section{Materials and Methods}

This was an observational prospective study done in VIMSAR, Burla from October 2016 to July 2018.Study population were all cases of gangrenous volvulus admitted during the period requiring emergency surgery. Samples taken were the gangrenous volvulus cases who undergone primary resection and anastomosis. Exclusion criteria was patients having hemodynamic instability and severe cardiopulmonary compromise and in obstruction due to malignant cases. Institutional ethical committee approval was taken and procedures were performed after taking informed and written consent from the patients and their relatives.
Preoperatively patients were resuscitated with intravenous fluid administration, urinary catheterization, nasogastric aspiration and broad spectrum antibiotics given. Diagnosis done by history, clinical examination and X-ray finding and also important haematological investigations done. After that exploratory laparotomy, derotation \& decompression of the gut with resection and primary end to end colorectal anastomosis done.

Resection and colostomy fashioning was performed on very sick patients and colon with heavy faecal loading.

Primary outcomes studied were anastomotic leak, paralytic ileus, chest complications, wound infection, colostomy complications and mortality.

Operative procedure: Under GA, laparotomy was done and sigmoid volvulus part was derotated and redundant colon was resected. Manual decompression of colon was done. Mobilisation of colon \& rectum gave healthy and tension free margins, performed end to end colorectal anastomosis. Bilateral abdominal drains were put and abdomen was closed. Postoperatively patients were monitored closely, kept on intravenous fluids, analgesics and antibiotics. Patients were kept nil per oral till the bowel sounds heard. Drains were taken out after sixth day.USG was done to assesfor any intra abdominal fluid collection. Patients were discharged after they remained stable and resumed their full diet. Patients were followed up for two months.

\section{Observation and Results}

Total out of 74 sigmoid volvulus cases, there were 32 cases of gangrenous sigmoid volvulus (43.2\%) who came under inclusion criteria.32 gangrenous cases include 20 males and 12 females (M:F $=1.66: 1$ ). Out of 32 gangrenous cases in 24 cases we did primary resection and anastomosis and in 8 cases we did Hartmann's procedure. 
Table 1: Distribution of gangrenous cases according to sex and type of procedure

\begin{tabular}{|l|c|c|c|}
\hline & $\begin{array}{c}\text { Resection and } \\
\text { anastomosis } \\
\text { (Gr 1) }\end{array}$ & $\begin{array}{c}\text { Hartmann's } \\
\text { procedure (Gr } \\
\text { 2) }\end{array}$ & Total \\
\hline Male & 15 & 5 & 20 \\
\hline Female & 9 & 3 & 12 \\
\hline Total & 24 & 8 & $\mathbf{3 2}$ \\
\hline
\end{tabular}

-In Resection and anastomosis group (Gr 1) out of

24 cases males were $15(62.5 \%)$ and females were $9(37.5 \%)$

Table 2: Age wise distribution

\begin{tabular}{|l|c|c|}
\hline Age groups & No of patients & Percentage (\%) \\
\hline $\mathbf{2 0 - 3 0}$ & 1 & $3 \%$ \\
\hline $\mathbf{3 1 - 4 0}$ & 2 & $6 \%$ \\
\hline $\mathbf{4 1 - 5 0}$ & 8 & $25 \%$ \\
\hline $\mathbf{5 1 - 6 0}$ & 13 & $40 \%$ \\
\hline $\mathbf{6 1 - 7 0}$ & 6 & $19 \%$ \\
\hline $\mathbf{7 1 - 8 0}$ & 2 & $6 \%$ \\
\hline Total & $\mathbf{3 2}$ & $\mathbf{1 0 0 \%}$ \\
\hline
\end{tabular}

-The incidence of gangrenous sigmoid volvulus in different age groups has been noted.

- The maximum incidence of gangrenous sigmoid volvulus was reported between age of 51-60 yrs comprising $40 \%$ with mean age calculated to be 53 years.

- In Gr 1 mean age found to be 50 years and in $\mathrm{Gr}$ 2 mean age found to be 64 years.

Table 3: Post operative complications

\begin{tabular}{|l|c|c|c|}
\hline Complications & $\begin{array}{c}\text { Resection and } \\
\text { anastomosis } \\
\text { group( Gr 1) } \\
(\mathbf{n = 2 4 )}\end{array}$ & $\begin{array}{c}\text { Hartmann's } \\
\text { procedure } \\
\text { group (Gr 2) } \\
(\mathbf{n = 8})\end{array}$ & $\begin{array}{c}\text { P } \\
\text { Value }\end{array}$ \\
\hline Wound infection & $7(29.16 \%)$ & $2(25 \%)$ & 0.820 \\
\hline Shock & $1(4.16 \%)$ & 0 & 0.557 \\
\hline $\begin{array}{l}\text { Anastomotic } \\
\text { leak }\end{array}$ & $2(8.33 \%)$ & $\mathrm{NA}$ & $\mathrm{NA}$ \\
\hline Paralytic ileus & $4(16.66 \%)$ & $1(12.5 \%)$ & 0.779 \\
\hline $\begin{array}{l}\text { Chest } \\
\text { complications }\end{array}$ & $1(4.16 \%)$ & $1(12.5 \%)$ & 0.399 \\
\hline $\begin{array}{l}\text { Colostomy } \\
\text { complications }\end{array}$ & $\mathrm{NA}$ & $1(12.5 \%)$ & $\mathrm{NA}$ \\
\hline Mortality & $3(12.5 \%)$ & $1(12.5 \%)$ & 1 \\
\hline
\end{tabular}

- The complications which were noted during post operative period were shock, wound infection, paralytic ileus, anastomotic leak, chest complications, colostomy complications and mortality.

- In both the groups wound infection found to be common complication. In $\mathrm{Gr} 1$ wound infection was 7 (29.16\%) and in Gr 2 it was 2 (25\%) having $P$ value 0.820 which is not significant.
- Most dreaded complication in Resection and anastomosis group was anastomotic leak in 2 patients $(8.33 \%)$

- In Gr 1 mortality in 3 cases (12.5\%) and in Gr 2 mortality in 1 cases $(12.5 \%)$.

\section{Discussion}

Sigmoid volvulus is one of the common cause of large bowel obstruction now a days. It is an emergency and if not treated early lead to bowel gangrene, perforation, peritonitis and accounts mortality. In non gangrenous cases non operative methods like sigmoidoscopy and rectal tube placement can be tried for decompression but in suspected gangrene it is contraindicated due to risk of bowel perforation and faecal contamination. Other methods like laparotomy and simple derotation and sigmoidopexy are having more post operative recurrence ${ }^{(23)}$.

So in gangrenous volvulus cases exploration followed by resection of nonviable part of bowel is must and then followed by either Hartmann's procedure or primary end to end anastomosis. The two staged Hartmann's procedure have a significant morbidity and mortality not only due to the procedure but also colostomy related complications. Reversal of Hartmann's procedure can be quite challenging and technical difficult which lengthens operation time ${ }^{(15)}$. It is mainly due to pelvic adhesions, sepsis or pelvic irradiation. In some studies there have been reported that colostomy takedown attempts in second sitting are abandoned during operations due to technical difficulty or rectal stump ischemia $^{(16)}$. There also literatures suggesting anastomotic leakage followed by restoration of bowel continuity after Hartmann's procedure as high as $4-16 \%$ and mortality rates as $4 \%(17)$. Multiple hospital admissions and operations required in staged operation which entail costs. One of the major drawback is distress to the patient related to colostomy and is a social stigma $^{(18)}$. Colostomy bags are often unavailable and unaffordable. 
In the past resection and colostomy was considered to be the standard emergency treatment for sigmoid volvulus ${ }^{(11,19)}$. However recently many surgeons preferring resection and primary anastomosis for acute sigmoid volvulus in emergency setting ${ }^{(20,21)}$. Many studies showed that sigmoid resection and primary anastomosis can be carried out safely when gut is viable ${ }^{(22,23,24)}$. Only a few studies have been done on gangrenous colon showing satisfactory results with resection and anastomosis of sigmoid volvulus ${ }^{(25,26)}$.

In this study for management of gangrenous sigmoid volvulus special focus on the outcome of emergency resection and anastomosis of bowel assessed. And Hartmann's procedure performed on very sick patients, colon with heavy faecal loading and in the cases where safe and tension free margin for anastomosis not possible.

Most common complication after surgery is wound infection, slightly higher following resection and anastomosis (29.6\%) as compared to resection and colostomy (25\%). Most dreaded complication following resection and anastomosis is anastomotic leak \& faecal fistula (8.33\%). Mortality almost equal after resection and anastomosis (12.5\%) and in Hartmann's procedure (12.5\%).

Mean hospital stay in resection anastomosis group was 12 days and in colostomy group was 8 days.

Colostomy procedures has more morbidity like stoma related complication(12.5\%), need for second surgery, risk of nonreversal and is not well accepted by the patients due to social stigma.

\section{Conclusion}

Resection and primary anastomosis in gangrenous sigmoid volvulus can be practised with few complications, a short hospital stay, avoidance of un-necessary colostomy and considering patient compliance. It has acceptable morbidity and mortality provided that anastomosis is done taking healthy and tension free margins in haemodynamically stable patients.

\section{References}

1. Bolt DE. The management of volvulus of the sigmoid colon. Br J Surg 1956;44:1725

2. Williams M, Steffes CP; Sigmoid volvulus in a 46 year old man. Hospital Physician, 2006; 33-36.

3. Jangjoo A, Soltani E, Fazelifar S, Saremi E, Afzal Aghaei M. Proper management of sigmoid colon volvulus: our experience with 75 cases. Int J Colorectal Dis2010; 25:407-9.

4. Valentine Pastore, Angela Basile, Raffaella Cocomazzi, MarlenaPastore, Fabio Bartoli. Sigmoid volvulus in a neonate: Case report and review of literature; African $\mathrm{J}$ ournal of paediatric surgery Oct/Decm 2013 (10) issue 4; 390392.

5. Yassaie O, Fawcett MT, Rossaak J; Management og sigmoid volvulus: is early surgery justifiable? ANZ J Surg. 2013; 83(1-2):74-78.

6. Spiegel A, Chugh T, Lebovics E; A review of colonic volvulus. PractGaastro., 2009: 42-46.

7. Katsikogiannis $\mathrm{N}$, Machairiotis $\mathrm{N}$, Zarogoulidis P, Sarika E, Stylianaki A, Zisoglou M, et al. Management of sigmoid volvulus avoiding sigmoid resection. Case Rep Gastroenterol. 2012;6:293-9.

8. Hadi A, Khan N, Shah SMA, Bangash A. Emergency management of sigmoid Volvulus: experience of Lady Reading Hospital . Peshawar. J Postgrad Med Inst 2006; 20:82-5.

9. Dulger M, Canturk NZ, Utkan NZ, Gonullu NN. Management of sigmoid colon volvulus. Hepatogastroenterology 2000; 47: 1280-3.

10. Bhatnagar BN, Sharma CL, Gautum A, Kakar A, Reddy DC. Gangrenous sigmoid volvulus: a clinical study of 76 patients .Int J Colorectal Dis.2004;19(2):134-42 
11. Cuschieri A, Steele RJC, Moossa AR. Essential surgical practice. 4th ed. London: Arnold Publication; 2002.

12. Mellor MF, Drake DG. Colonic Volvulus in children: value of barium enema for diagnosis and treatment in the children. AJR. Am J Roentgenol.1994;162(5):11579

13. Catalano O. Computed tomographic appearance of sigmoid volvulus.Abdom Imaging. 1996;21(4):314-7

14. Kassi AB, Lebeau R, Yenon KS, Katche E, Diane B, Kouassi JC (2011) Morbidity and mortality of Hartmann's procedure for sigmoid volvulus at the University Hospital of Cocody, Abidjan. West Afr J Med 30 (3):169-172

15. Richter S, Lindemann W, Kollmar O, Pistorius GA, Maurer CA, Schilling MK. One-stage sigmoid colon resection for perforated sigmoid diverticulitis (Hinchey Stages III and IV). World J Surg 2006;30:1027-32.

16. Aydin HN, Remzi FH, Tekkis PP, Fazio VW. Hartmann's reversal is associated with high postoperative adverse events. Dis Colon Rectum 2005;48:2117-26.

17. Meijer WS, Vermeulen J, Gosselink MP. Primary resection and side-to-end anastomosis next to and end-colostomy in the management of acute malignant obstruction of the left bowel: an alternative in selected patients. Tech Coloproctol 2009;13:123-6.

18. Forster M E, Leaper D J, Williamson R C. Changing patterns in colostomy closure : the Bristol experience 1975 - 1982. Br J Surg 1985; $72: 142$ - 5 .

19. Baker DM, Wardrop PJ, Burrell H, Hardcastle JD. The management of acute sigmoid volvulus in Nottingham. J R CollSurg Edinb1994; 39:304-6.
20. Khan M, Ullah S, Jan MAU, Naseer A, Ahmed S, Rehman A. Primary anastomosis in the management of acute sigmoid volvulus without colonic lavage. J Postgrad Med Inst 2007; 21:305-8.

21. Oren D, Atamanalp SS, Aydinli B, Yildirgan MI, Basoglu M, Polat KY, Onbas O. An algorithm for the management of sigmoid colon volvulus and the safety of primary resection. Experience with 827 cases. Dis Colon Rectum.2007;50(4):489-97 .

22. Akcan A, Akyildiz H, Artis T, Yilmaz N, Sozuer E (2007) Feasibility of single-stage resection and primary anastomosis in patients with acute non complicated sigmoid volvulus. Am J Surg 193 (4):421426. doi:10.1016/j.amjsurg.2006.08.077

23. Naseer A, Ahmad S, Naeem M, Safirullah (2010) One stage emergency resection and primary anastomosis for sigmoid volvulus. J Coll Physicians Surg Pak 20 (5):307-309. doi:05.2010/jcpsp.307309

24. De U, Ghosh S (2003) Single stage primary anastomosis without colonic lavage for left-sided colonic obstruction due to acute sigmoid volvulus: a prospective study of one hundred and ninety-seven cases. ANZ J Surg 73 (6):390-392

25. Sule AZ, Misauno M, Opaluwa AS, Ojo E, Obekpa PO (2007) One stage procedure in the management of acute sigmoid volvulus without colonic lavage. Surgeon 5 (5):268270

26. Raveenthiran V (2004) Restorative resection of unprepared left-colon in gangrenous vs. viable sigmoid volvulus. Int J Colorectal Dis 19 (3):258-263. doi:10.1007/s00384-003-0536-6. 